\title{
Ethics of Care Approaches in Psychotherapy a
}

Anna Magdalena Elsner and Vanessa Rampton

The Oxford Handbook of Psychotherapy Ethics

Edited by Manuel Trachsel, Jens Gaab, Nikola Biller-Andorno, Serife Tekin, and John Z. Sadler

Subject: Philosophy, Philosophy of Mind, Moral Philosophy Online Publication Date: Jul 2020

DOI: $10.1093 /$ oxfordhb/9780198817338.013.15

\section{Abstract and Keywords}

The ethics of care poses a special case for psychotherapy. At first glance, key elements of care ethics such as acknowledging our dependence on others, attention to emotions, and creating a supportive environment for healing overlap substantially with key characteristics of psychotherapy. Care ethics' emphasis on attentiveness and empathetic concern, and related acts such as listening and talking to patients point in the direction of salutary therapeutic relationships, and also of valorizing psychotherapy as a practice. Yet psychotherapy has a long history of critical engagement with the therapeutic relationship, using terms and concepts other than "care." This chapter shows that while relatively little work has been done on care ethics approaches in psychotherapy, such approaches complement traditional attentiveness to the (psycho)therapeutic relationship by asking to what extent psychotherapists are practicing care and what this entails. Conversely, because psychotherapy has long been concerned with intersubjectivity, as exemplified by the concepts of transference and countertransference, it offers valuable theoretical and practical resources for care ethics approaches.

Keywords: care, feminism, ethics, psychotherapy, boundaries

\section{Introduction}

Psychotherapy, conceived as psychological treatment, and its close relatives including psychoanalysis, counseling, family and couple therapy, have become influential ways of addressing symptoms by focusing on relationships. Psychotherapy embraces a view of human nature distinct from other areas of health or social care (Barker 2011: 32), because a core unifying theme among psychotherapies is that the feelings and attitudes therapist and patient have toward one another, and how they are expressed, are crucial for treatment and outcome (Gelso 2011: 4; Gelso and Carter 1985: 159). Indeed, it has been claimed that psychotherapy is the only medical subspecialty in which "the use of the therapeutic alliance itself is regarded as not only necessary, but as alone sufficient, for healing" (Radden and Sadler 2010: 55). While such statements are resisted by psy- 
chotherapists who prefer more measurement-based models such as cognitive behavioral therapy, the fact remains that psychotherapy's traditional focus on the therapeutic relationship adds "immeasurably to the patient's vulnerability and to the responsibility imposed on the treater" (Radden 2002: 53).

Care ethics is an approach to ethical problems that prioritizes and values human relations. It stresses the importance of taking into account emotions and deepening empathetic bonds in order to navigate human interdependence. It therefore has a natural affinity with psychotherapy, given that, as Liz Bondi notes, the "emotional relationship dynamics on which psychotherapies focus presuppose interdependence as a feature of human life" (Bondi 2008: 262). At the practical level, psychotherapy is a female-dominated profession, just as caring functions have traditionally been associated with women; a recent report by the American Psychological Association calculated that there are roughly twice as many female practicing psychotherapists as male ones in the United States and that the gender gap is widening (Lin et al. 2015: 1). Specific branches of psychotherapy, such as for example, feminist, systemic, person-centered or emotion-focused approaches, have sought to explore emotional relationship dynamics by extending the therapist-patient relationship to address the complexities of individual's lives (see the chapter by Kramer and Elliott on emotion-focused therapy in this volume). Efforts to include people that play important roles in the patient's emotional relationships are exemplified by family or couple therapies, which have an obvious affinity with care ethics even if they have not been explicitly linked to that approach. Indeed, the implications of the ethics of care for psychotherapy generally remain underexamined (exceptions include Bloch and Green 2006; Robertson and Walter 2007). An analysis of these implications seems particularly relevant given that there is a topical debate within psychotherapy that opposes measurementbased models focusing on clearly identifying problems and desirable actions/outcomes, to those who consider the therapeutic relationship itself as sufficient for healing (Leichsenring and Steinert 2017).

In what follows we discuss, first, the history of caring and care ethics and, second, relevant moments in the history of psychotherapy that grapple with the reality of human relationality, before analyzing the conceptual and practical implications of bringing the two together. We claim that an ethics of care approach offers valuable insights into the unequal and emotionally complex role of psychotherapeutic relationships generally. In a context where the centrality of the psychotherapeutic alliance is contested, care ethics comes down firmly on the side of psychotherapy's relational nature. Conversely, because psychotherapy has long been concerned with intersubjectivity, as exemplified in the concepts of transference and countertransference, it therefore also offers valuable theoretical and practical resources for care ethics approaches.

\section{Caring and Care Ethics: A Brief History}

Care ethics can be formally dated to 1982, and the publication of Carol Gilligan's In a Different Voice: Psychological Theory and Women's Development, as explored in further de- 
tail below. Yet the ideas of care and caring, and the ethical implications thereof, have a long history that sheds light on present day challenges for care ethics approaches in psychotherapy.

In his historical analysis of the idea of care, Warren Reich argues that it has had two principal meanings in healthcare settings:

(i) taking care of the patient in the technical sense, that is providing competent, appropriate diagnostic or therapeutic interventions, and

(ii) caring for or about the patient, which suggests a virtue of devotion and concern for the other as a person, who is being attended to and helped in a difficult situation (Reich 1995: 361).

Reich cites the early twentieth century as the moment when these two meanings of care became disconnected from one another. In the context of increasingly sophisticated techniques and scientific knowledge, physicians began "to divorce the disease from the patient," thus marginalizing personal care in the sense of "caring for" the person (Reich 1995: 362; see also Reiser 1978: 227). In 1926, Harvard professor and physician Richard Cabot expressed an influential view whereby he acknowledged the importance of caring for "the minds, the emotions, the wills, the souls" of patients, but also the fact that doing so is impossible for doctors and nurses, since "their attention is too strongly concentrated on the excessively difficult and delicate tasks of diagnosis and treatment" (Cabot 1926: 16). Cabot saw the solution as letting physicians and nurses focus on the physical body, and delegating the task of caring for the patient's soul to ministers, theological students, friends and relatives, social workers, and psychologists (Cabot 1926: 18, 6-7).

Cabot's suggestion that physicians should be exempted from "caring for" patients was called into question by his colleague Francis Peabody. In his essay "The Care of the Patient" Peabody argued that one "of the essential qualities of the clinician is interest in humanity, for the secret of the care of the patient is in caring for the patient" (Peabody 1927: 882; our emphasis). His intervention was underpinned by his sense of the need to deal with the patient as a whole person; as he put it, the task of the doctor is to transform "that case of mitral stenosis in the second bed on the left" into the complex problem of "Henry Jones, lying awake nights while he worries about his wife and children" (Peabody 1927: 878). Peabody was therefore concerned to make physicians aware of "the commonest and simplest factors that initiate and perpetuate the functional disturbances," including "sorrow, disappointment, anxiety, self-distrust, thwarted ideals or ambitions in social, business or personal life, and particularly what are called maladaptations to these conditions" (Peabody 1927: 881); he singled out psychiatry as the one medical discipline sensitive to the fact that in many cases "it is not the disease but the man or the woman who needs to be treated" (Peabody 1927: 880). Nevertheless, he stopped short of analyzing more specifically what the sort of personalized care he advocated would mean for mental health disciplines. 
Following Peabody's intervention, the importance of caring-as-concern was further developed by a subsequent generation of physicians, often as a reaction to the dangers of depersonalized care in the hospital setting. This focus was associated with a concern for the patient as a person-that is, more than simply a highly complex organism-and increased attention to the moral requirements governing relations between human beings. In a widely read book published in 1970, The Patient as Person: Explorations in Medical Ethics, theologian Paul Ramsey described the physician-patient relationship as a covenant, based on "righteousness between man and man" (Ramsey 1970: xlv). The idea that caring involves an encounter with "the vulnerable humanness of the other" (Reich 1995: 366) was simultaneously expanded upon in the context of other care-oriented professions such as nursing. Caring, in this context, was characterized as "the most demanding and deeply human aspect," that is "the expressive art of being fully present to another person" (Davis 1981: 1). According to nursing theorist and anthropologist Madeleine Leininger, caring has a significant impact on curing, which even led her to propose that "there can be no curing without caring" (Leininger 2001: 45). Based on her work as a psychiatric nurse, Leininger developed the idea that caring is "what makes people human, gives dignity to humans, and inspires people to get well and to help others" (Leininger 2008: 1).

As caring came to imply an increased sensitivity to the feelings of others, its proponents were aware of the dangers associated with excessive attachment on the part of the caregivers (see Halpern 2001). In a 1964 lecture at Harvard Medical School entitled "Caring for the Patient," physician Hermann Blumgart argued that "[e]motional appreciation of the patient's feelings without becoming engulfed by them is of paramount importance" and referred to "neutral empathy" or "compassionate detachment" as a desirable safeguard against this (Blumgart 1964: 451). A decade later, in an intervention on "'Caring' as a part of Health Care Quality," clinician W. W. Menninger developed this insight by emphasizing that the physician must

maintain some emotional distance from the patient, i.e. to sense the patient's experience empathetically without becoming so involved sympathetically that the physician's rational and effective clinical judgment is impaired by emotional involvement. (Menninger 1975: 837)

Yet by and large the contributions that highlighted the need to care for the patient in Peabody's sense were concerned less with the necessity of remaining emotionally detached and more with reclaiming what they felt had been lost in modern, technology-driven health care. Menninger, for example, concluded his essay by reflecting:

It may be advisable for every physician or health care provider to periodically be a patient, to reexperience that role, and to be sensitive to some of the forgotten aspects of that experience. (Menninger 1975: 837)

The appearance of Gilligan's In a Different Voice (1982) provided a significant impetus for contemporary ethics of care by exploring care in relation to other power dynamics at work in society. Trained as a psychologist, Gilligan conducted various empirical studies 
on moral reasoning and reported that her female subjects were more concerned with the context of a moral dilemma and more willing than males to incorporate the viewpoint of others. As she put it, "The ideal of care is thus an activity of relationship, of seeing and responding to need, taking care of the world by sustaining the web of connection so that no one is left alone" (Gilligan 1982: 62). She referred to this type of moral reasoning as an "ethic of care" and contrasted it with an ethic of justice that she associated with traditional Western approaches to normative ethics as shaped by the moral concerns of men. Crucially, Gilligan valorized what she presented as women's moral reasoning, and portrayed care ethics as being as valuable as more traditional justice-oriented moral theories.

Gilligan did not aim to elaborate a comprehensive normative approach, but her empirical findings were taken up by others and her work was "followed by a torrent of feminist-inspired writings about personal relationships, caring and nurturing, the differences between care and justice, relational self-identity and the importance of emotional responsiveness to others" (Friedman 2000: 209). Among them was, for example, the phenomenological description of caring by Nel Noddings, which claimed that all caring activities are characterized by a "displacement of interest from my own reality to the reality of the other" (Noddings 1984: 14). But Noddings and others also explored the wider implications of personal caring at a social and political level, which means that sometimes the ethics of care is seen as an example of a normative theory that rivals dominant ones such as deontological, consequentialist, and virtue ethics. At times, given that the ethics of care is sensitive to context, particular situations, and narratives, it is presented as a form of virtue ethics (Biller-Andorno 2012: 394). Some of its proponents have gone further to argue that this approach should resist presenting itself as a moral theory, since there are no context-independent rules for caring which is always "embodied, relational, configurational, skillful, meaningful and contextual" (Benner and Wrubel 1989: 6).

Despite divergences, what binds the ethics of care together is, as Marilyn Friedman puts it, "an account of a distinctive style or approach to ethical problems and concerns" (Friedman 2000: 208). Its fundamental insight is "to encourage a critical reflection of self in its embodiedness and relatedness while trying to empathically understand the individual moral world of the other" (Biller-Andorno 2012: 395). Virginia Held, one of its main proponents, has noted that what is at stake is an "ethics of care, and not just care itself," since "the various aspects and expressions of care and caring relations need to be subjected to moral scrutiny and evaluated, not just observed and described" (Held 2005: 539). She highlights five distinctive features of the ethics of care (Held 2006: 538ff.): first, the emphasis of the ethics of care "is on the compelling moral salience of attending to and meeting the needs of the particular others for whom we take responsibility." Second, the epistemological focus of the ethics of care is emotions; it appreciates moral emotions (such as sympathy, empathy, sensitivity, and responsiveness) and relational capabilities that enable morally concerned persons to understand what actions are advisable in interpersonal contexts. Third, the ethics of care rejects the view that moral problems can be resolved by abstract reasoning and reliance on universal rules in favor of the particular and the actual. Fourth, the ethics of care reconceptualizes 
traditional public/private distinctions by emphasizing moral issues that arise in relations among the unequal and the dependent, which may be emotion-laden and involuntary. Finally, care ethics considers persons as relational and interdependent, and therefore partly constituted by their relationships with others, in stark contrast to self-sufficient, unencumbered conceptions of persons in individualist liberalism, for example.

The emphasis that care ethics places on emotions, interpersonal relationships, and valuing context-specific interdependencies seems, at first glance, to dovetail with the aim of the psychotherapist to provide "compassionate, individualized care" (Cautin 2011: 4). Moreover, as Liz Bondi puts it, "psychotherapies constitute an arena in which emotion work is explicit and foregrounded" (Bondi 2008: 252). Yet psychotherapy has developed its own terms and concepts for theorizing the role of care in the physician-patient relationship, largely without reference to the term care itself. It is to this history that we now turn.

\section{Caring in Psychotherapeutic Approaches and their Antecedents}

Early-to-mid-twentieth-century psychoanalysis was characterized by hierarchical and patriarchal perspectives rather than a relational, person-centered approach. Yet the recognition of the importance of the therapeutic relationship, and the difficulty of defining and applying boundaries to that relationship, were already characteristic of psychoanalysis in this foundational period for psychotherapy (Zur 2007: 3).

Sigmund Freud (1856-1939) captured the ambivalent concept of "transference" in his Studies on Hysteria (1895) where he described how patients project and reenact certain core attitudes and issues in their relationship with the analyst. He observed that by redirecting feelings and desires towards the analyst, the patient effectively seeks to repress or divert ideas that emerge in the course of therapy, and thereby engages in an important and necessary form of resistance to therapy, which he described in his seminal paper "Remembering, Repeating, and Working Through" (Freud 1958 [1914]). Freud claimed that transference was constitutive of a successful psychoanalysis and went as far as to argue that "it would be senseless to try to evade it; for an analysis without transference is an impossibility" (Freud 1959 [1925]: 42). To best channel this resistance, Freud insisted on the notion of "neutrality," and recommended "that the analysis be conducted in an atmosphere of abstinence"; that is, one in which the analyst should maintain a "relative anonymity," which he described using metaphors such as the "blank screen," the "mirror," and the "surgeon" (Wolitzky 2011: 72-73).

Freud recognized that, in addition to the patient, the therapist is also vulnerable to ambivalent emotions. He identified "countertransference" as the transference of unconscious emotions from the analyst to the patient. Countertransference, according to Freud, was an impediment to therapy (Freud 1957 [1910]) since it undermines any claims about the analyst being able to provide a truly blank screen onto which therapeutically valuable 
transference can be projected. This emphasis on distance as a therapeutic technique was not universally shared, as exemplified by Freud's close associate Sándor Ferenczi (18731933), who argued that "a physician's love heals the patient" (Holmes and Lindley 1989: 135). A contemporary view would certainly dismiss Ferenczi's methods, which involved kissing his patients and letting them kiss him (Wolitzky 2011: 75), as unethical and transgressive. Nevertheless, Ferenczi's concept of "mutual analysis" anticipated later shifts in psychoanalytic thinking which viewed countertransference as a positive resource that "had the effect of bringing the psychoanalyst down from some imagined pedestal to a position at the same level, or within the same field, as the patient" (Bondi 2008: 256). Feminist theorist Julia Kristeva has taken up the Freudian concepts and linked them specifically to care. She defines care as "a concern for others, and a consideration for their 'ill-being'" and considers "the process of transference and counter-transference involved in the psychoanalytic cure [an] example of the economy of care" (Zournazi 2002: 65-66). The concept of countertransference remains, moreover, central to the practice of psychotherapy today, as the ability to recognize countertransference problems and deal with them is a key aspect of how therapists become aware of their own projective tendencies (Gabbard 1999: xiii; Mitchell 1993).

From a slightly different angle, other post-Freudian approaches to psychotherapy explicitly relied on "relational reworkings of analytic concepts and technique" in order to link psychotherapies more explicitly to practices of care (Botticelli 2006: 76; Aron 1996). One highly influential approach to psychotherapy, which rejected psychoanalysis and set up the caring relationship as its central feature, is the person/client-centered tradition founded by Carl Rogers (1902-1987). Rogers emphasized that the therapist must be congruent or integrated into the relationship, a condition he describes as "genuineness." Rogers associates this awareness or genuineness with the ability to reflect on one's own feelings and, rather than suppress "uncaring" feelings that inevitably arise, he suggests they should be owned and thought about (see Bondi 2008: 253). Rogers further emphasized the importance of the therapist's unconditional positive regard for patients, which implies unconditional acceptance and "caring for the client as a separate person, with permission to have his own feelings, his own experiences" (Rogers 1957: 98). Importantly, this implies accepting the client's expression of "negative, 'bad', painful, fearful, defensive, abnormal feelings" (Rogers 1957: 98) as much as the good ones, something that was further explored within self-reflective care ethics approaches. Finally, Rogers claimed that analysts must be able to identify with their clients yet avoid misunderstanding their clients' feelings as their own, thereby acknowledging the importance of protecting the emotional safety of the therapist (see also Rogers 1951, 1961; Zimring and Raskin 1992). This has a notable affinity with Gilligan's portrayal of morally mature adults as able to achieve a self-reflective, self-responsible balance between care for others and care for themselves (Gilligan 1982: ch. 3).

Some have argued that Rogers's work anticipated what is called the "relational turn" that grouped together those psychotherapies focusing on the psychotherapeutic relationship itself, as opposed to those that emphasized measurement-based behavioral therapies. The relational turn, as some have noted, was a fundamental step for assigning care a central 
role in psychotherapy. Analyst Sandro Botticelli, for example, observes that this has allowed therapists to think of their work as "providing care." "Our consulting rooms," he writes, "have become a place to which people turn to feel cared for and appreciated" (Botticelli 2006: 73-74; see also Bondi 2008: 252). The point is further developed by psychotherapist Jonathan Slavin who observed that the technical modalities that characterize the therapist-patient relationship, whether they are called transference or countertransference or something else, are but a changing vocabulary secondary to the main end of therapeutic practice, which is a "healing human relationship in and of itself" (Slavin 1997: 813). In what follows, we examine the conceptual and practical implications of bringing together the ways in which psychotherapies and care ethics conceive of a healing relationship.

\section{Implications of Ethics of Care Approaches for Psychotherapy Ethics}

Several proponents of the ethics of care have argued for extending it to the practice of psychotherapy and related disciplines (Adshead 2002; Bloch and Green 2006; Robertson and Walter 2007). Broadly speaking, these interventions highlight the limitations of ethical principlism and argue that an ethics of care approach would move caring relationships to the center of psychotherapy, and thereby engender more humane outcomes. Moreover, if, as some recent contributions in psychotherapy claim, the psychotherapeutic relationship can usefully be thought of as a caring relationship, an ethics of care provides an appropriate set of values for engaging the complex and ambivalent feelings that caregivers and recipients experience. In the following, we review the implications ethics of care approaches have for psychotherapeutic practice, focusing specifically on four key aspects, namely the role of psychotherapy and its wider social and political implications, as well as conceptions of personhood, autonomy, and boundaries in the therapeutic relationship.

\section{Society and Politics}

In considering how a care ethics orientation might be usefully applied to psychotherapy it is necessary to acknowledge that care ethics has sometimes been portrayed as a specifically feminine perspective on ethics, based on the practical experience of care work-e.g., mothering-undertaken by women (Ruddick 1989). Virginia Held has observed that the ethics of care "builds relations of care and concern and mutual responsiveness to need on both the personal and wider social levels" (Held 2006: 43). Care ethics' prioritizing of relational dynamics as they are experienced within the immediate family, friendships, and social groups are therefore considered the foundations for the establishment of a "caring society," which would regard "the tasks of bringing up children, educating its members, meeting the needs of all" as foundational for its success (Held 2005: 550). Crucially, "a caring society would attend to the health of the social relations between its members" (Held 2006: 136), in which mental health plays an important part. As Held and 
others have noted, the social changes a focus on care requires are profound, also because of their inherently political implications. The observation by political theorist Joan Tronto that "caring activities are devalued, underpaid, and disproportionately occupied by the relatively powerless in society" (Tronto 1993: 113) still holds today. Like many other forms of care work, practitioners of psychotherapies are numerically dominated by women, particularly outside the field of psychiatry where the gender gap is least pronounced (Lin et al. 2015; Pelling et al. 2006). In terms of salary, psychotherapists and related professions-marriage and family therapists ( $\$ 50,090$ median pay per year), psychologists $(\$ 79,010)$, mental health counselors $(\$ 44,630)$-earn far less than related medical specialties such as psychiatrists $(\$ 220,380)$, who themselves have small revenues compared to other medical professions (US Bureau of Labor Statistics 2018). This political and economic reality entails practical obstacles for a care-based approach to mental health because, as Botticelli notes:

To the extent that the work we perform increasingly is needed in this more "nurturant" form, it becomes susceptible to the devaluation to which such work has perennially been subject. This devaluation has everything to do with gender: the low value placed on care work in our society goes hand in hand with the fact that traditionally women do it. Among the consequences for psychoanalysis: reduced reimbursement rates, fewer men entering the profession, lower "prestige" for the field within the larger culture. (Botticelli 2006: 74)

The psychoanalyst Jessica Benjamin has described this problem by highlighting what she refers to as a seeming opposition between "inspired healing and professional technique" (Benjamin 1997: 794). In her assessment, this is rooted in the fact that many female analysts feel uncomfortable taking on the responsibility for theoretical legitimation, seeing as they are far more "comfortable with their stance as empathic, reparative clinicians-embracing happily the 'ethic of care'” (Benjamin 1997: 795). This perceived division between caring and scientific rigor, which continues to inform contemporary divides between those committed to the therapeutic alliance and those who favor measurement-based therapies, has deep roots in the history of psychotherapy, as intimated above. Louis Breger, in his revisionist biography of Freud, observed that Freud's development of psychoanalysis was responsible for attempting to fit its fundamentally practical focus on caring into the more formal structures of a respected scientific discipline (Breger 2000). In Breger's account, Freud was loath to reduce psychoanalysis to caregiving and thus resisted the-empirically compelling-evidence that his treatments had the most curative value when patients felt liked, valued, and appreciated rather than when analysts used, for example, the methods of abstinence and blank slate Freud prescribed. Botticelli argues that this is why "care has been undertheorized in psychoanalysis," namely because it "seems at odds with the rigors of theory and technique" (Botticelli 2006: 75). As self-reflective care ethics provides valuable theoretical resources, and care ethics-embodied therapies are increasingly subjected to scientific testing of efficacy, it seems increasingly likely that this divide can be bridged. 


\section{Personhood}

Care ethics reinforces a generalized premise among psychotherapies concerning "a holistic conception of the person, in the sense that a person is understood as an embodied psychosocial whole embedded in a social and relational nexus" (Radden 2002: 54). Its conception of the moral agent is able "to capture significant features of man's interaction in general, such as reciprocity, dependency, connectedness and asymmetry" (Pettersen 2011: 52). Assigning caring relations a central rather than derivative role is, therefore, one way to acknowledge the importance of attachments and human interdependence within the psychotherapeutic relationship (Fry 1989: 20-21). More specifically, by foregrounding the importance of relationships, an ethics of care approach in psychotherapy seems particularly pertinent to feminist (see chapter on feminist approaches in this volume), family, and systemic forms of psychotherapy, as it encourages the view that relationships are both part of the problem and crucial for treatment.

In Pettersen's assessment, this model of a related moral agent enables "care ethicists [to] become analytically equipped to address a wide variety of relationships and the type of harm some may inflict" (Pettersen 2011: 54). As Bondi highlights, such an approach seems uniquely positioned to assess the emotional dynamics at stake in the psychotherapeutic encounter, because

rather than demanding of care-givers specific kinds of feelings towards care recipients, such as love or filial piety, psychotherapeutic approaches call instead for the capacity and willingness to acknowledge and tolerate the full range of feelings caring and being cared for may stimulate, at the same time maintaining an underlying respect for the care recipient, a respect expressed in part through bearing witness to their experience. (Bondi 2008: 260)

Acknowledging that psychotherapists may experience a large range of feelings towards their patients seems particularly relevant, especially since they might be confronted with patients who refuse treatment even if they would find it helpful. Since the concept of care is particularistic, in the sense that it is "always specific and relational," as Benner and Wrubel (1989: 3) put it, it has also been accused of failing to provide "any real guide to action in a clinical setting" (Robertson and Walter 2007: 210). Others have argued that care remains ambiguous and "hopelessly vague" (Allmark 2002: 63) and by positing that care itself is constitutive of a moral good, the approach runs the risk that the focus on caring no longer allows for the critical assessment of the object of care. Yet care ethics' attempt to act as "a template for acknowledging the interests of all affected" can also be understood as a way to deal with the complexities of human relationality in a constructive way that acknowledges the drawbacks of "caring too much" (Pettersen 2011: 57). Emphasis on a web of relations calls for a more pluralistic and holistic view of situations than other ethical approaches; the value of care ethics may therefore lie in "constraining, or perhaps humanizing, more utilitarian or principlist based calculations of ethical action" (Robertson and Walter 2007: 210). 


\section{Autonomy}

By drawing attention to the value of human relations, care ethics questions the central role the concept of individual autonomy has held in other moral theories. This critique of a normative concept associated with independence and self-sufficiency might seem fundamentally at odds with the goals of psychotherapy, in so far as psychotherapy not only aims to respect the autonomy of patients, but the "promotion of [their] autonomy" and "developing [autonomous] functioning" (Thompson 1990: 13). Yet care ethics does not reject the notion of autonomy altogether, rather it relies on a relational conception which highlights the social, emotional, and embodied aspects of the concept (Mackenzie and Stoljar 2000; Osuji 2018). Care ethics does not "see the person making moral decisions as a radically autonomous, self-legislating individual. Rather she is tied to others" (Allmark 2002: 64). With its assumption of human interdependency, care ethics is, as Verkerk puts it, "more concerned about the dangers of abandonment than the dangers of interference" (Verkerk 2001: 291). This perspective might prove particularly relevant to psychotherapy since by "developing a more relational model of autonomy, interventions in care can be shown to be in the interest of patients, that is, they can be seen as interventions for attaining autonomy instead of threatening it" (Verkerk 2001: 293). For this reason, Bondi has emphasized the advantages of working with a notion of relational autonomy in psychotherapies, which respects the autonomy of those seeking help and yet "presuppose[s] interdependence as a feature of human life" (Bondi 2008: 262).

In this sense, care ethics leaves open the possibility of more paternalistic interventions because they may be required by the situations of interdependence and mutual support that define our lives. In Verkerk's analysis, a care ethics perspective offers several distinct arguments for the involuntary treatment of mental patients, what practitioners in social psychiatric care have termed "compassionate interference" (Verkerk 2001: 292). First, the ethics of care is more directed to how people "can relate to each other, rather than how they can be left free" (Verkerk 2001: 293). Second, the care perspective stresses the idea of responsibilities rather than rights, and the therapeutic relationship is one "in which responsibilities towards each other are set," as opposed to rights of non-interference, for example. Finally, a relational model of autonomy can show that interventions in care are "in the interest of patients, that is, they can be seen as interventions for attaining autonomy, instead of threatening autonomy" (Verkerk 2001: 293). While more restrictive interventions fall into the domain of psychiatry rather than psychotherapy, a care ethics conception of relational autonomy highlights that part of the importance of such interventions is always to allow patients to "be helped in caring and committed relationships to regain their self-esteem" (Verkerk 2001: 293). For psychotherapists, caring may at times involve breaching confidentiality and advocating involuntary treatment on patients' behalf. 


\section{Boundaries}

Given care ethics' focus on acceptance and emotional availability, maintaining boundaries and preventing boundary crossings and violations plays a crucial role in its application in psychotherapy. Boundary violations, which are often preceded by boundary crossings (Gutheil and Gabbard 1993), always "represent a failure to regulate the space between the patient and the therapist, so that they are either too close and enmeshed or too far away and distant" (Adshead 2016: 455). Paying close attention to boundaries as structuring and maintaining the therapeutic relationship seems particularly vital in a care ethics framework, given its emphasis on non-verbal forms of communication, such as "touch, movement, facial expression, tone of voice, quality and pace of non-verbal utterances, what is not said and so on" (Bondi 2008: 260). It has been argued, however, that an ethics of care might be able to integrate the regulation of boundaries rather than needing to formalize them as rules. By "including attention to both professional duties of care and patient rights," it might be able to "offer a more coherent justification for prohibiting therapist-patient sexual relationships," for example, than one informed by principlism (Adshead 2002: 59). An ethics of care approach highlights that the therapist needs to "understand how her own relational needs may have caused her to come to take action which was ethically unjustifiable" (Adshead 2002: 59), and this awareness is necessary for managing the aftermath of such an event in a constructive way. In this sense, care ethics might provide a framework for dealing effectively with mistakes such as boundary violations, as it requires both patient and therapist to reflect on how they "should" behave in the context of an ongoing relationship, which in Adshead's estimation is "the very substance of a notion of the duty of care" (Adshead 2002: 59)

This insight is compatible with the notion that caring for others can entail neglect and even harm of the self. As Kottler remarks: "The experience of any practitioner would attest to the emotional as well as intellectual strains of living constantly with clients' crises, confusion, and intense suffering" (Kottler 1986: 66). This might even be exacerbated by the requirements of professionalism and confidentiality, as even the best clinical detachment might not be able to fully protect therapists from feeling overwhelmed and exhausted by their patients' suffering. If a care ethics approach enables us to understand "caring" as a reciprocal, rather than one-sided, activity then it can make a real contribution to the ethics of psychotherapy since it allows us to account for the fact that even within the asymmetrical relationship between psychotherapist and patient, the seemingly dominant figure of therapist is also vulnerable and may need to seek professional help her/himself.

\section{Conclusion}

Jennifer Radden has observed that the "uniqueness of psychiatry calls for a unique ethics" (Radden 2002: 53). As a perspective that highlights the limitations of abstract moral theories and instead valorizes attentiveness, empathy, and concern, and specifically encourages listening and talking to the patient, the ethics of care could be said to offer such an approach. Its emphasis on communication skills, emotional sensitivity, and the 
moral weight of personal relationships all have their place within contemporary psychotherapy, particularly because both fields understand and valorize human relationships as a key part of healing.

Yet recourse to the ethics of care provides no straightforward answers to some of the fundamental challenges in psychotherapy ethics. This is compounded by the fact that its focus on caring cannot function as a comprehensive normative theory. Not only is it difficult to allocate care as a limited resource, it can be easily manipulated, and it does not provide tools for assessing the moral weight of that about which we care (Card 1990; Houston 1990). Care ethics can, however, provide an analytical framework for reflecting on the nature of the therapeutic relationship, as well as the role of psychotherapy within the healthcare system more broadly. Conversely, psychotherapy can help care ethics address some of its unanswered questions, including the fact that sharing the feelings of the patient and acknowledging one's own vulnerability always contain the threat of escaping from the carer's control.

The authors would like to thank Mary Bartram for her helpful comments on the chapter.

\section{References}

Adshead, G. (2002). "A Different Voice in Psychiatric Ethics." In Healthcare Ethics and Human Values: An Introductory Text with Readings and Case Studies (ed. K. W. M. Fulford, D. L. Dickenson, and T. H. Murray, pp. 56-62). Malden, MA: Blackwell Publishers.

Adshead, G. (2016). "Ethics and Boundaries." In Oxford Specialist Handbooks: Medical Psychotherapy (ed. J. Yakeley, J. Johnston, G. Adshead, and L. Allison, pp. 441-460). Oxford: Oxford University Press.

Allmark, P. (2002). “Can There Be an Ethics of Care?” In Healthcare Ethics and Human Values: An Introductory Text with Readings and Case Studies (ed. K. W. M. Fulford, D. L. Dickenson, and T. H. Murray, pp. 63-69). Malden, MA: Blackwell Publishers.

Aron, L. (1996). A Meeting of Minds: Mutuality in Psychoanalysis. Hillsdale, NJ: The Analytic Press.

Barker, P. (ed.) (2011). Mental Health Ethics: The Human Context. New York: Routledge.

Benjamin, J. (1997). “Psychoanalysis as a Vocation.” Psychoanalytic Dialogues 7: 781-802.

Benner, P. and Wrubel, J. (1989). The Primacy of Caring: Stress and Coping in Health and Illness. Menlo Park, CA: Addison-Wesley.

Biller-Andorno N. (2012). “Care, Ethics of.” In Encyclopedia of Applied Ethics (2nd ed., vol. 1; ed. R. Chadwick, pp. 390-396). San Diego, CA: Academic Press.

Bloch, S. and Green S. A. (2006). “An Ethical Framework for Psychiatry.” British Journal of Psychiatry 188: 7-12. 
Blumgart, H. L. (1964). “Caring for the Patient.” New England Journal of Medicine 270: 449-456.

Bondi, L. (2008). “On the Relational Dynamics of Caring: A Psychotherapeutic Approach to Emotional and Power Dimensions of Women's Care Work." Gender, Place and Culture 15: 249-265.

Botticelli, S. (2006). "Globalization, Psychoanalysis, and the Provision of Care: Roundtable on Global Woman." Studies in Gender and Sexuality 7: 71-80.

Breger, L. (2000). Freud: Darkness in the Midst of Vision. Hoboken, NJ: Wiley.

Cabot, R. C. (1926). Adventures on the Borderlands of Ethics. New York: Harper \& Brothers.

Card, C. (1990). “Caring and Evil.” Hypatia 5: 101-108.

Cautin, R. L. (2011). “A Century of Psychotherapy, 1860-1960.” In History of Psychotherapy: Continuity and Change (2nd ed.; ed. J. C. Norcross, G. R. VandenBos, and D. K. Freedheim, pp. 3-38). Washington, DC: American Psychological Association.

Davis, A. J. (1981). “Compassion, Suffering, Morality: Ethical Dilemmas in Caring.” Nursing Law and Ethics 2: 1-2, 6, 8.

Freud, S. (1957 [1910]). "The Future Prospects of Psycho-Analytic Therapy.” In The Standard Edition of the Complete Psychological Works of Sigmund Freud, vol. 11 (1910): Five Lectures on Psycho-Analysis, Leonardo da Vinci and Other Works (ed. J. Strachey et al., pp. 139-152). London: Hogarth.

Freud, S. (1958 [1914]). "Remembering, Repeating and Working-Through (Further Recommendations on the Technique of Psycho-Analysis II)." In The Standard Edition of the Complete Psychological Works of Sigmund Freud, vol. 12 (1911-1913): The Case of Schreber, Papers on Technique and Other Works (ed. J. Strachey et al., pp. 145-156). London: Hogarth.

Freud, S. (1959 [1925]). “An Autobiographical Study.” In The Standard Edition of the Complete Psychological Works of Sigmund Freud, vol. 20 (1925-1926): An Autobiographical Study, Inhibitions, Symptoms and Anxiety, The Question of Lay Analysis and Other Works (ed. J. Strachey et al., pp. 1-74). London: Hogarth.

Friedman, M. (2000). "Feminism in Ethics: Conceptions of Autonomy." In The Cambridge Companion to Feminism in Philosophy (ed. M. Fricker and J. Hornsby, pp. 205-224). Cambridge: Cambridge University Press.

Fry, S. T. (1989). “Toward a Theory of Nursing Ethics.” Advances in Nursing Science 11: 9-22. 
Gabbard, G. O. (ed.) (1999). Countertransference Issues in Psychiatric Treatment. Washington, DC: American Psychiatric Association.

Gelso, C. (2011). The Real Relationship in Psychotherapy: The Hidden Foundations of Change. Washington, DC: American Psychological Association.

Gelso, C. and Carter, J. A. (1985). "The Relationship in Counseling and Psychotherapy: Components, Consequences, and Theoretical Antecedents." The Counseling Psychologist 13: $155-243$.

Gilligan, C. (1982). In a Different Voice: Psychological Theory and Women's Development. Cambridge, MA: Harvard University Press.

Gutheil, T. G. and Gabbard G. O. (1993). "The Concept of Boundaries in Clinical Practice: Theoretical and Risk-Management Dimensions." The American Journal of Psychiatry 150: 188-196.

Halpern, J. (2001). From Detached Concern to Empathy: Humanizing Medical Practice. Oxford: Oxford University Press.

Held, V. (2005). "The Ethics of Care." In The Oxford Handbook of Ethical Theory (ed. D. Copp, pp. 537-566). Oxford: Oxford University Press.

Held, V. (2006). The Ethics of Care: Personal, Political, and Global. Oxford: Oxford University Press.

Holmes, J. and Lindley, R. (1989). The Values of Psychotherapy. Oxford: Oxford University Press.

Houston, B. (1990). “Caring and Exploitation.” Hypatia 5: 115-119.

Kottler, J. (1986). On Being a Therapist. San Francisco, CA: Jossey-Bass.

Leichsenring, F. and Steinert, C. (2017). "Is Cognitive Behavioral Therapy the Gold Standard for Psychotherapy? The Need for Plurality in Treatment and Research." JAMA 318: 1323-1324.

Leininger, M. (2001). Culture Care Diversity and Universality: A Theory of Nursing. New York: National League for Nursing Press.

Leininger, M. (2008). “Overview of Leininger's Theory of Culture Care Diversity and Universality.” Retrieved from http://www.madeleine-leininger.com/cc/overview.pdf

Lin, L., Stamm, K., and Christidis, P. (2015). Demographics of the U.S. Psychology Workforce: Findings from the American Community Survey. Washington, DC: American Psychological Association.

Mackenzie, C. and Stoljar N. (eds.) (2000). Relational Autonomy: Feminist Perspectives on Autonomy, Agency, and the Social Self. New York: Oxford University Press. 
Menninger, W. W. (1975). "'Caring' as Part of Health Care Quality.” JAMA 234: 836-837.

Mitchell, S. (1993). Hope and Dread in Psychoanalysis. New York: Basic Books.

Noddings, N. (1984). Caring: A Feminine Approach to Ethics and Moral Education. Berkeley, CA: University of California Press.

Osuji, P. I. (2018). "Relational Autonomy in Informed Consent (RAIC) as an Ethics of Care Approach to the Concept of Informed Consent." Medicine, Health Care and Philosophy 21: 101-111.

Peabody, F. W. (1927). “The Care of the Patient.” JAMA 88: 877-882.

Pelling, N., Brear, P., and Lau, M. (2006). “A Survey of Advertised Australian Counsellors.” International Journal of Psychology 41: 204-215.

Pettersen, T. (2011). "The Ethics of Care: Normative Structures and Empirical Implications." Health Care Analysis 19: 51-64.

Radden, J. (2002). “Notes Towards a Professional Ethics for Psychiatry.” Australian \& New Zealand Journal of Psychiatry 36: 52-59.

Radden, J. and Sadler, J. (2010). The Virtuous Psychiatrist: Character Ethics in Psychiatric Practice. Oxford: Oxford University Press.

Ramsey, P. (1970). The Patient as Person: Explorations in Medical Ethics. New Haven, CT: Yale University Press.

Reich, W. T. (1995). “Care: I, II and III.” In Encyclopedia of Bioethics (2nd ed.; ed. W. T. Reich, pp. 319-344). New York: Simon \& Schuster.

Reiser, S. J. (1978). Medicine and the Reign of Technology. Cambridge: Cambridge University Press.

Robertson, M. and Walter, G. (2007). “Overview of Psychiatric Ethics II: Virtue Ethics and the Ethics of Care." Australasian Psychiatry 15: 207-211.

Rogers, C. R. (1951). Client-Centred Therapy: Its Current Practice, Implications, and Theory. Boston, MA: Houghton Mifflin.

Rogers, C. R. (1957). "The Necessary and Sufficient Conditions of Therapeutic Personality Change." Journal of Consulting Psychology 21: 95-103.

Rogers, C. R. (1961). On Becoming a Person. Boston, MA: Houghton Mifflin.

Ruddick, S. (1989). Maternal Thinking: Toward a Politics of Peace. New York: Ballantine Books.

Slavin, J. H. (1997). “Models of Learning and Psychoanalytic Traditions: Can Reform Be Sustained in Psychoanalytic Training?” Psychoanalytic Dialogues 7: 803-817. 
Thompson, A. (1990). Guide to Ethical Practice in Psychotherapy. New York: John Wiley \& Sons.

Tronto, J. (1993). Moral Boundaries: A Political Argument for an Ethic of Care. New York and London: Routledge.

US Bureau of Labor Statistics (2018). Office of Occupational Statistics and Employment Projections. Retrieved from https://www.bls.gov/ooh/life-physical-and-social-science/ home.htm

Verkerk, M. A. (2001). “The Care Perspective and Autonomy." Medicine, Health Care and Philosophy 4: 289-294.

Wolitzky, D. (2011). "Psychoanalytic Theories of Psychotherapy." In History of Psychotherapy: Continuity and Change (2nd ed.; ed. J. C. Norcross, G. R. VandenBos, and D. K. Freedheim, pp. 65-100). Washington, DC: American Psychological Association.

Zimring, F. M., and Raskin, N. J. (1992). "Carl Rogers and Client/Person-Centred Therapy.” In History of Psychotherapy: A Century of Change (ed. D. K. Freedheim, pp. 629656). Washington, DC: American Psychological Association.

Zournazi, M. (2002). “Joyful Revolt: A Conversation with Julia Kristeva." In Hope: New Philosophies for Change (ed. M. Zournazi, pp. 64-77). Annandale: Pluto Press Australia.

Zur, O. (2007). Boundaries in Psychotherapy: Ethical and Clinical Explorations. Washington, DC: American Psychological Association.

\section{Anna Magdalena Elsner}

Institute of Biomedical Ethics and History of Medicine, University of Zurich

\section{Vanessa Rampton}

Institute for Health and Social Policy, Department of Philosophy, McGill University 